\title{
Characteristic of Safety Recovery Zone and Roadside Hazard Cases in Malaysia Road: A Review
}

\author{
${ }^{1 *}$ A.K.Kunji, ${ }^{2}$ A.Kusbiantoro, ${ }^{2}$ A.Zulkiple and ${ }^{1}$ H.M.Ramli \\ ${ }^{1}$ Perunding RJA, 25100 Pahang, Malaysia \\ ${ }^{2}$ Faculty of Engineering Technology, University Malaysia Pahang, 26300, Kuantan, Pahang, Malaysia \\ *Corresponding Author: kamaliem12@gmail.com
}

\begin{abstract}
The increasing number of highway crashes and the rising rate of fatality on run-off-road accidents has alarmed institutions to introduce design guidelines, evaluate their outcomes and improve the guidelines accordingly. This paper presents a case study on some of the existing roadside hazards in Malaysia, their impact to motorists, and reviews the current related provisions in the published design guidelines. Observations and in-depth study were made to the selected existing roadside hazards and assess their compliance to the available design guidelines and recommend improvement to some areas. The scope of the study covers on roadside trees, lighting and signboard poles, drainage structures, kerbs and safety barriers. The previously planted trees of less than 100 millimetres diameter within the clear zone of 9 and 6 meters to rural and urban roads respectively have grown in size to more than $500 \mathrm{~mm}$ diameters over 15 years, and today they have become hazards and causing deaths or serious injuries to passengers. The lighting and signboard poles installed near to the travel lane have resulted in high impact collisions to the extent of splitting vehicles and killing the motorists. The current roadside drainage structures are made of concrete and some with rubble lined walls are harmful and have been killing and injuring motorists when they are placed within the roadside safety recovery zone or corridor that are meant for skidding errant vehicle to make recovery traversing back to travel lane. The study showed some roadside barriers are not correctly applied and have become hazards instead of protecting the motorists. The outcomes of the case study suggest improvement to the design guidelines and roadside physical condition to minimise hazards to motorists.
\end{abstract}

Indexed Terms- Roadside hazards, design guidelines, recovery zone

\section{INTRODUCTION}

Road accident has been one of the highest hazards in the world. This leads to a continuous effort by various parties to improve road design guidelines in order to minimise road fatalities. Everyday 3,500 road users killed and 137,000 injured due to road accidents throughout the world [1]. On 10 May 2010, the United Nations General Assembly announced officially that the period 2011-2020 as the decade of action for road safety to reduce traffic fatalities around the world through networking at national, regional and global levels $[1,2]$.

In the year of 2013, Malaysia recorded 477,204 road accidents, 6,915 people killed, giving an average of 19 people killed every day, more than 12,000 road user injuries of which 4,000 serious injuries with estimated loss close to RM9.0 billion [1]. Realising the importance of road safety, Department of Road Safety under Ministry of Transportation Malaysia in collaboration with Malaysian Institute of Road Safety Research issued Malaysian Road Safety Plan 2014-2020. The five safety plan pillars are road safety management, safer roads and mobility, safer vehicles, safer road user and postcrash response [1]. The study was initiated from the first Global Ministerial Conference on Road Safety in Moscow on 19 and 20 November 2009. 
The United States recorded in 2008, about $23.1 \%$ of the crashes were run-off-road cases [3]. In the year 1998, European Union countries recorded 33.8\% of all fatalities were the result of run-off-road accidents [4]. In 2011, about $60 \%$ of the crashes in the United States were single-vehicles took place on the shoulder, median, or off the roadway [5, 6]. In the years 2001-2010, European Union recorded that $32 \%$ of crashes were single-vehicle and $42 \%$ of single-vehicle off-road were fatal crashes [7-9]. Vehicles straying off from travel lanes and encroaching into roadsides mostly resulted in fatal crashes due to high crash impacts caused by a combination of high vehicle travelling speed, steep roadside slope gradient and obstructing objects such as trees, utilities and signs poles etcetera.

Studies have been conducted to investigate various distraction that have great impact onto the safety of driving [10-14]. Distraction due to multitasking such as the use of mobile phone while driving is among the popular cause of accidents [15]. The recent experiments of 241 drivers driving for 43,000 hours while using mobile phones showed increased number of crashes as compared to other distractions $[15,16]$. The fatal collisions between single-vehicle motorcyclist with fixed objects of mostly trees, poles, posts and roadside barriers in the roadway for Australia accounts for 39\% [17]. Roadside Design Guide issued by American Association of State Highway and Transportation Officials AASHTO published in 2011 classifies trees, traffic barriers, non-traversable embankment slopes, ditches and drainage channels, kerbs, culverts and drain inlets located within the safety recovery zone to be hazards. [3]

Based on this practice and guideline, this research paper is looking into the situation of Malaysian roadside hazards and accidents based on several case studies. The study covers the five popular kind of hazards such as trees, lighting and signboard poles, drainage structures, kerbs and walls and roadside barriers. The study evaluates both the installed hazards and the design guide recommendation by assessing their performance based on the accident outcomes.

\subsection{Roadside Hazards in America and Europe}

\subsubsection{American Practice}

In 2013, trees represents 50\% of the fixed object crash deaths by object struck in the United States [18]. In promoting uniformity in practice, each states highway agencies to develop own guideline for design, landscape, construction, and personnel for maintaining the property. In general, an existing tree with projected mature size of $100 \mathrm{~mm}$ or more at stub height is classified as hazardous fixed object and should be removed for new construction and reconstruction [3]. For the purpose of reducing the number and level of run-off-road crashes, AASHTO recommends implement restriction planting trees in hazardous area, and if trees exist in the zone, the exercise is to eliminate or shield them from severe impact [3].

Two methods in approaching roadside trees problem are firstly keeping the motorist on the road and secondly mitigate the danger inherent on crash impact with the tree [3]. The first method of keeping motorist on the roadway is by providing pavement marking, rumble strips, signs, delineators, and roadway improvements. Pavement markings on the centreline and edge line are effective and least costly particularly for night time and lack of vision driving. Shoulder rumble strips may warn the skidding motorist that they leaving roadway. Installing advance warning signs and roadway delineators may alert motorists for extra caution on the incoming high risk area in particular sharp turning curves. Roadway improvements such as increasing super elevation, shoulder widening, and paving may reduce crashes though may not cost-effective in all cases.

The two options applicable for off-roadway treatments are either tree removal or shielding. The removal option is taken when a particular tree is an obstruction and located at likely to be hit area. Such trees often recognised from past histories and scars on the stem indicating previous crashes. Isolated tree located close to the roadway is to be removed. Provide a well-designed barrier when a tree or a 
group of trees located in a vulnerable location if severity striking the tree is greater than striking the barrier [3].

\subsubsection{European Practice}

The study based on 265,000 run-off-road cases from seven European countries (Austria, Finland, France, the Netherlands, Spain, Sweden and the United Kingdom), 67\% were hitting objects cases [19]. The crashes on drains were $11.1 \%$ of which 17 fatal, 39 serious injured and 44 with slight injuries. It reported that trees are the most dangerous roadside objects, and $17 \%$ of trees associated accidents were fatal and mostly involved with impact speeds of $70 \mathrm{~km} / \mathrm{h}$ and above. The text quoted that U.S. Department of Transportation's Fatality Analysis Reporting System (FARS), study on the fixed object crash deaths in 2008 shows that trees represent the highest percentage of $48 \%$. Preserved old and established trees which are not permitted to be removed or relocated to be shielded to ensure safety to crashing motorists.

Based on $10 \%$ of the accidents reported by participating European countries, most fatal crashes involving trees of diameter $0.3 \mathrm{~m}$ and larger for motorist with seatbelt and $0.2 \mathrm{~m}$ without seatbelt [4]. The reported fatal crashes recorded maximum offset distance from the roadside at $6.8 \mathrm{~m}$ for motorists with seatbelt worn and $10.8 \mathrm{~m}$ for motorists without seatbelt worn. At locations with known speed data, the fatal crashes occurred at and above $70 \mathrm{~km} / \mathrm{h}$, whilst serious injuries took place at impact speed 40 $\mathrm{km} / \mathrm{h}$ or greater.

\section{METHOD OF STUDY}

A selected accident cases and a stretch of about $10 \mathrm{~km}$ Kuantan-Gambang highway were visited to identify and evaluate the roadside hazards located within the safety recovery zone measuring less than 9 meters offset perpendicular from the edge of the travel lane. A comparative study was made between the guideline recommendations to that being constructed at site. Contents of the design guidelines related to subjects of case study were reviewed taking outcomes as the basis. The study recommends solutions to part of the discovered problems because a well-designed research is to provide effective solutions [20].

Based on the research conducted by Kunji et al on the safety recovery zone for Malaysia road, the widths of corridor should be varied based on the speed of vehicle and slope of the corridor [21]. Table 1 shows the recommended width of safety recovery zone that would be used as reference in analysing the safe positioning of the roadside obstructing objects.

Table 1: Safety Recovery Zone Corridor Widths Z for Specified Roadside Slope Gradients S at Various Vehicle-Travelling Speeds.

\begin{tabular}{|c|c|c|c|c|c|c|c|}
\hline \multirow{2}{*}{ 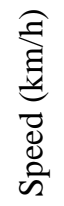 } & \multicolumn{7}{|c|}{ Safety Recovery Zone Corridor Width or $Z$ (m) } \\
\hline & 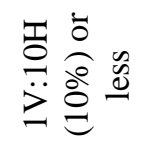 & 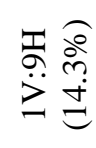 & 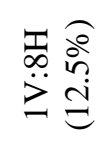 & 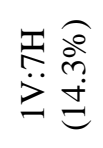 & 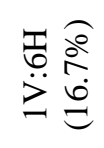 & 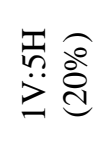 & 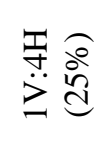 \\
\hline 50 & 1.640 & 1.844 & 2.102 & 2.435 & 2.878 & 3.488 & 4.412 \\
\hline 60 & 2.357 & 2.552 & 2.801 & 3.121 & 3.547 & 4.133 & 5.021 \\
\hline 70 & 3.074 & 3.261 & 3.500 & 3.806 & 4.215 & 4.778 & 5.630 \\
\hline 80 & 3.790 & 3.970 & 4.198 & 4.492 & 4.884 & 5.423 & 6.239 \\
\hline 90 & 4.507 & 4.678 & 4.897 & 5.178 & 5.553 & 6.068 & 6.849 \\
\hline 100 & 5.386 & 5.491 & 5.625 & 5.797 & 6.027 & 6.343 & 6.821 \\
\hline 110 & 5.940 & 6.096 & 6.294 & 6.550 & 6.890 & 7.358 & 8.067 \\
\hline
\end{tabular}




\section{CASE STUDY IN MALAYSIA}

\subsection{Case Study on Hazard Type 1: Development of Roadside Trees in Malaysia}

The clear zone provision in the section 4.1 of the Malaysian landscaping design guide known as Intermediate Guideline to Road Reserve Landscaping issued by Cawangan Jalan Ibu Pejabat JKR restricts planting of trees bigger than $100 \mathrm{~mm}$ diameter within the roadside clear zone intended for skidding vehicle recovery path back to travel lane [22]. It is stated in the section that the clear zone width for rural and urban to be 9 and 4 meters respectively. The argument for the planted tree to be less than $100 \mathrm{~mm}$ diameter because it can be easily broken upon collision is not true throughout its life as it is a growing object. Since its introduction, in line with the call made by the Malaysia's prime minister to make the country a "Garden State" by the year 2005, trees were planted beside roads nationwide. The diameter of a tree is growing in size every day and over years the diameter multiplied.
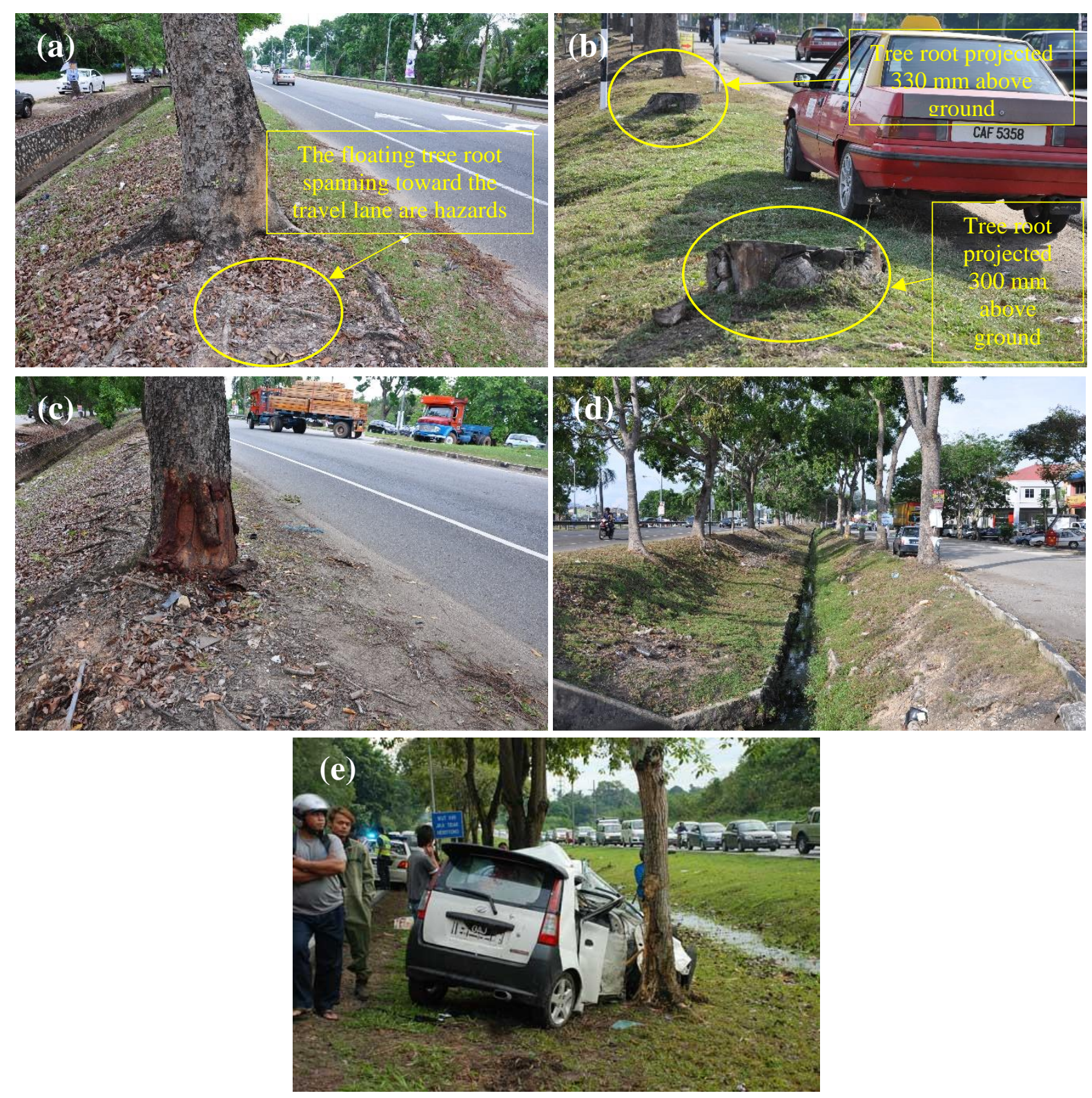

Figure 1: (a) Potential hazard of a tree; (b) Stump of trees; (c) Evidence of damaged tree due to collision; (d) Row of trees along the road near Kuantan; (e) Fatal accident at Bintulu, Sarawak [24]. 
Figure 1 (a) shows a tree at km 5 Gambang-Kuantan road has stem diameter of $490 \mathrm{~mm}$ measured one metre above the ground, the size grew from the original size of less than $100 \mathrm{~mm}$ and now has multiplied about 5 times over about 15 years period, the present size is at the state of extremely hazardous object. The tree stem location is about 3.8 meters away from the travel lane, but it effective distance from the travel lane reduces as its root spanning toward the travel lane. The root itself is a hazard, as vehicle especially motorbike will lose control running over it. It is believed that the skinned off part of the tree is the old mark of being hit by vehicle.

Some of the trees planted along the main road have grown up big as shown by the stumps 800 $\mathrm{mm}$ and $600 \mathrm{~mm}$ as shown behind and in front of the car respectively in Figure 1 (b). The trees were cut but not uprooted, and they remain as hazards to roadside. The tree stumps are hazards as they can cause vehicle to airborne upon colliding and plunge into the nearby drain. It is recommended that all the existing trees spaced at about 12 meters interval along the roadside of the main road to be removed and let alone the sling road trees as shown in Figure 3 remain as required National Landscape Policy for development area in its vision of transforming Malaysia into beautiful garden nation by year 2020 [23].

Figure 1 (c) shows the tree fresh peeled skin at the bottom part of the tree indicates that it was recently hit by a vehicle as evidenced by the broken pieces of the vehicle scattered body parts on the ground nearby the tree. The trees along the main road are hazard to passing by motorists and shall be removed. Meanwhile Figure 1 (d) shows a damaged car after it rammed a tree, killing the driver on the spot at Kidurung, Bintulu, and Sarawak in August 2012. The tree shown in the figure is having stem diameter of about $250 \mathrm{~mm}$ and planted at about $3 \mathrm{~m}$ away from the nearest edge of travel lane which is within the Malaysian landscape design guide restricted for planting zone of $9 \mathrm{~m}$ roadside corridor for rural road. The earlier grown size was less than $100 \mathrm{~mm}$ diameter but overtime it has grown bigger and has become a hazard. Despite the diameter is not really that big, but side collision is more critical compared to front collision due to the thin layer and soft nature of the side door. Head on collision has thicker layer from the front bumper, the engine compartment and the dash board before reaching the driver.

The American Roadside Design Guide recommends implementation of the safety recovery zone corridor (therein called as Clear-Zone) to allow the errant vehicle to take control of his situation once stray off from the carriageway [3]. It suggests that safety recovery zone corridor has to be free of fixed objects including trees to avoid collision. Conversely, the Malaysian's design guide titled as Nota Teknik Jalan 19/97 under clause 4.1 recommends planting of less than $100 \mathrm{~mm}$ diameter trees within the roadside safety recovery zone corridor, which contravene with the AASHTO Roadside Design Guide, the document from which Nota Teknik was referenced. As quoted in the earlier section, the small trees will grow bigger and become roadside hazards.

It is recommended that the Malaysian landscape design guide Clause 4.1 which reads as "Clear zones is defined as the area adjacent to the road pavement to the first tree (of diameter greater than 100 $\mathrm{mm}$ ) planted" shall be rephrased to "Clear zones is defined as the area adjacent to the road pavement to the first tree planted" i.e. with the elimination of the phrase "(of diameter greater than $100 \mathrm{~mm}$ )". In addition, to remove the last paragraph under the same section that reads as "Only shrubs and trees of diameter less than $100.00 \mathrm{~mm}$ are recommended to be planted within the clear zone". The recommendation is to totally restrict planting of tree within the safety recovery zone corridor.

\subsection{Case Study on Hazard Type 2: Lighting and Signboard Poles}

Run-off-road crashes with trees represent more than $13 \%$ of fixed object crash deaths by object struck in the year of 2013 [18]. The rate of crashes is associated with the number of poles and posts in use, their proximity to the travelling lane, and their impact non-absorbing nature.

Figure 2 (a) shows a car rammed into a lighting pole splitting the car into two at Dengkil/Cyberjaya exit. The lighting pole is positioned within the 3 meters road shoulder, a space that is too tight for skidding vehicle to manoeuvre back to the travel lane. The road is under the category of 
a primary rural road with speed limit of $110 \mathrm{~km} / \mathrm{h}$ and traversing on roadside slope less than $1 \mathrm{~V}: 10 \mathrm{H}$, based on Table 1, the recommended roadside safety recovery zone corridor width is 5.94 meters. If the lighting pole is installed outside the safety corridor of 5.94 metres, the car could have escaped from hitting the lighting pole. Technically the pole can be placed outside the emergency lane with the upper part of the pole cantilevered over the lane or opt for the spot light kind of design. Utility poles safety issues can be resolved through collaboration of effort between the highway agencies with the respective utility companies.
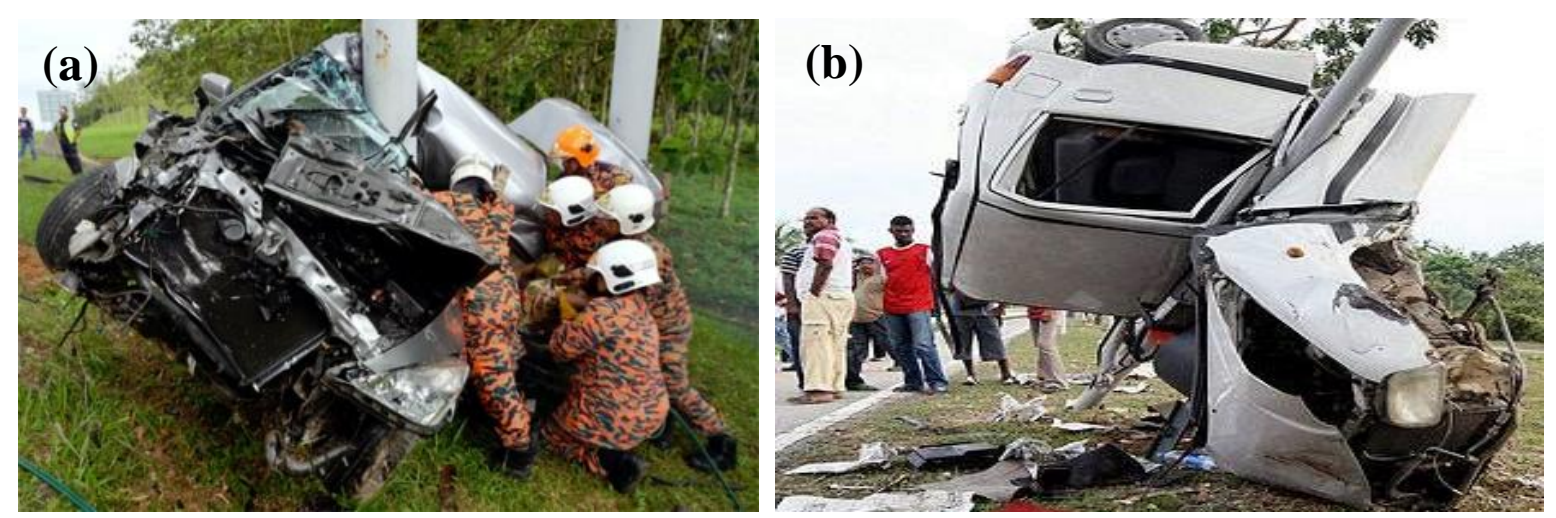

Figure 2: (a) A car ramped into lighting pole splitting the car into two (b) A car crashed into a road signpost. Source: New Straits Times, May 3, 2013.

Figure 2 (b) shows the car crashed into signboard pillar causing five in family killed on 02 May 2013 at North-South Expressway, Kulai Jaya, Johor. The pillar shall be kept away from the travel lane as far as the width of safety recovery zone corridor. Based on the study outcome shown in Table 1, for rural expressway travelling speed of $110 \mathrm{~km} / \mathrm{h}$ and roadside slope of $1 \mathrm{~V}: 4 \mathrm{H}$, the required free of obstruction corridor width is 8.07 meters compared to the signboard post nearest position of 6 meters. If the safety zone corridor size were applied, the car would have escaped the accident. However, the grass within the corridor must be cut to ensure it does not sway the car. The signboard can be designed with single instead of double posts with display board projected away or cantilevered from the pole as typically adopted by many traffic lights. The least effort is adapting to shielding the post if fall within a danger zone.

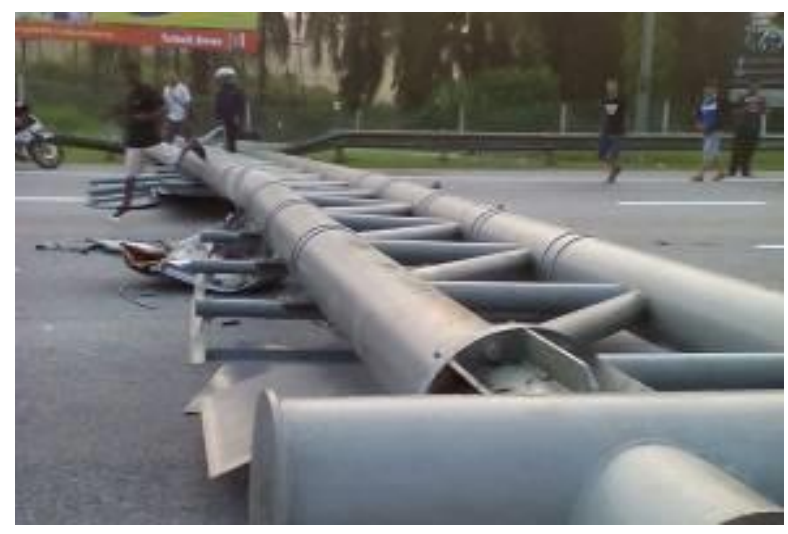

Figure 3: A signboard girder collapsed onto a passing car

Figure 3 shows a metal signboard girder collapsed onto a passing car after a trailer crashed into its post causing 3 in the family died on 10 October 2015 at km $399.8 \mathrm{Tg}$. Malim/Behrang, North-South highway. The girder was supported on metal pole with the nearer to travel lane pole positioned at about 5 meters from against the study recommended spacing of 6.89 meters for road speed limit having roadside slope 
of $1 \mathrm{~V}: 6 \mathrm{H}$ as in Table 1 . If the study recommended spacing is applied, the vehicle might escaped from hitting the steel column and save the motorists life.

The requirement on lighting and signage for roadwork is addressed in the guidebook for geometric design of roads under clause 6.3 and 6.5 respectively [25]. For safety of the road, the guide requires provision lighting to interchanges, intersections, railroad grade crossings, narrow or long bridges, and tunnels and at roadsides having interferences. The exact offset distance from the carriageway is not stated in the section has resulted industry practice installing the pole one meter outside the side table or road shoulder i.e. 2.5 to 4 meters from the carriageway given that the road shoulder widths for both rural and urban roads are between 1.5 to 3 meters. There is no clear zone requirement in the placement of lighting and signage poles construes that no consideration in providing sufficient space for skidding vehicle to recover back to travel lane. The following case studies reveal fatal accidents involving poles and post, and prove the need for them to be placed outside the safety recovery zone. Unlike trees, utility poles are made of metal and can be designed to keep their stems away from the road shoulder by bending the top end toward the road shoulder to light up the emergency lane.

For future and existing roads, where providing roadside safety recovery zone are not practicable, shield the pole to reduce the potential impact from vehicle collision. It is recommended that the design guide clause 6.3 be added with statement that "all lighting poles and post to be placed outside the safety recovery zone, and if limitation arise, they are to be shielded to minimise collision impact". Sign and luminaire are typical highway accessories, placing them wisely may save some lives. Having them installed too near to the roadway, they will become obstruction and open to collision Sign and luminaire supports to be relocated at least possible crash areas. Power and telephone cables can be buried to overcome from becoming obstacles.

\subsection{Case Study on Hazard Type 3: Culverts and Drains}

\subsubsection{Safety Concept}

The toe, shoulder and roadside drains serve to collect and transfer storm water runoff on the carriageway and the embankments to the edge of the formation [26]. The Malaysian standard known as A Guide on Geometric Design of Roads issued by the Road Engineering Association of Malaysia (REAM) under section 6.2 requires drainage design to be integral part of road geometric design [25]. It states that adequate drainage to be provided to ensure highway is free of flood with minimum construction and maintenance costs. Despite in this text does not address on drainage system to be treated as roadside hazard, an engineer where relevant account for safety in his works. As the drain to be integral with road geometric design, it is recommended that a paragraph that prohibit its encroachment into the safety recovery zone or else to provide safety features to be added in Malaysia design guidelines so as to ensure the matter is not overlooked.

\subsubsection{Road Crossing Culvert Inlets and Outlet Protection}

In collaboration with Jabatan Kerja Raya Malaysia, REAM has issued five volumes Guidelines for Road Drainage Design. An inlet or outlet unless protected are harmful to skidding vehicle. Despite the five volumes design guidelines do not prohibit placement of culvert inlet and outlet at the roadside corridor, an engineer shall provide treatment to ensure skidding motorist do not suffer serious injury or fatal situation caused by the hard and sharp edges of the concrete structures.

It is quite common in the Malaysian practice for culverts to run across road when carriageway elevation is higher than surrounding area to allow under-passage of water stream or underside crossing road from one side to the other. The current practice of building highway with a minimum elevation of one metre higher than flood level has caused increasing number of the culverts usage to allow underpassage of stream in ensuring balancing level of flood on both sides of the road. Typically, the crossing culvert design comprise of the tubing section and headwall complete with wings. The uncovered headwall and wings are introduced for backing earth behind them has become a hazard to the roadway. 
Most of the culverts in Malaysia are having inlet and outlet without metal grating cover as shown in Figure 4 (a). The projection of the concrete head and wing walls above ground surface may cause vehicle to be airborne upon striking. In building-up inlet and outlet as a traversable fore-slope, all culverts inlets and outlets shall be designed to intercept with the roadways embankments and flushed with metal gratings $[3,27]$.
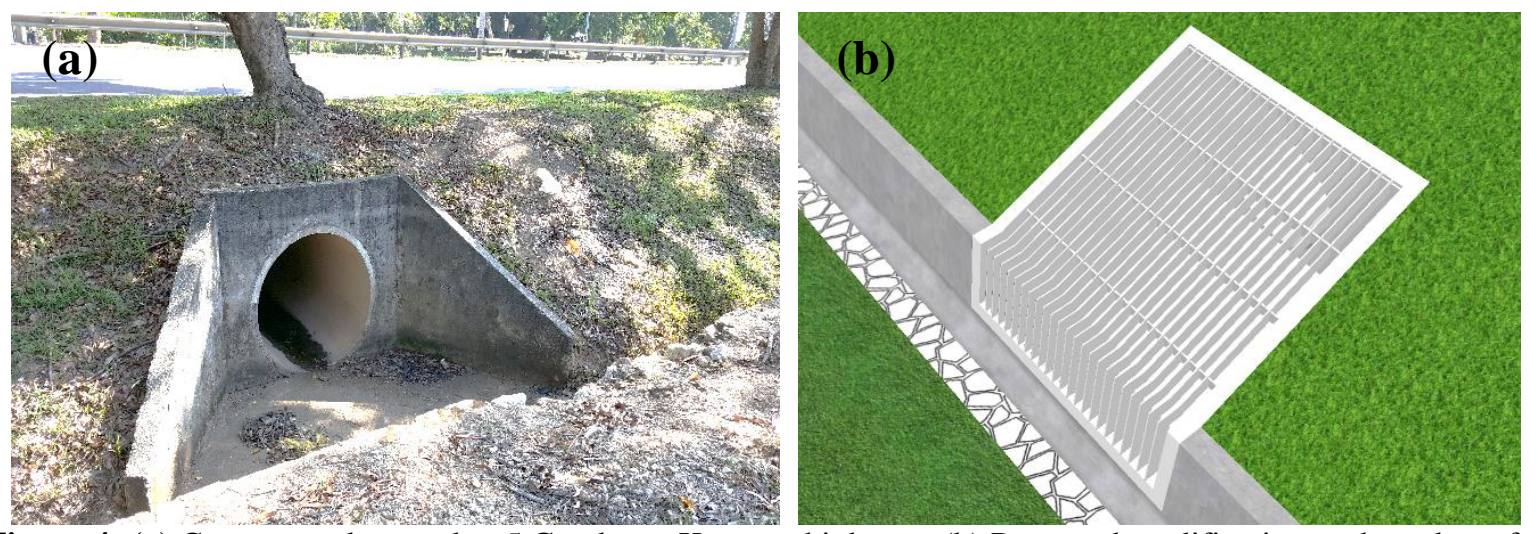

Figure 4: (a) Concrete culvert at km 5 Gambang-Kuantan highway; (b) Proposed modification to the culvert for (a).

It is proposed that the existing culvert inlet and outlet head walls constructed within the roadside safety recovery zone corridor, the wing wall to be modified as shown in Figure 4 (b). The metal screen serves two functions, namely for screening the debris and the surface is traversable by skidding vehicle for in an attempt to recover back to the travel lane. The metal blade is set to be vertical to minimise debris clinging to the grill and affecting the proper flow of the discharge. As shown in the detail, the selected design is $12 \mathrm{~mm}$ plate thickness spaced at $100 \mathrm{~mm}$ centres. Both wing walls are set straight instead of at an angle with the direction of storm water flow to prevent entry of eroded earth into the culvert.

\subsubsection{Roadside Drain}

Figure 5 shows skidded car where the driver could not control the car due to steep roadside slope of $1 \mathrm{~V}: 1 \mathrm{H}$ against the good design practise of $1 \mathrm{~V}: 4 \mathrm{H}$ the limit for traversable slope and hitting the drain's hard rubble pitching wall and bounced back causing three passengers died and one badly injured. Should the one sided rubble line wall was replaced with turfed earth, the downslope $1 \mathrm{~V}: 1 \mathrm{H}$ embankment was built with the study recommended new slope of $1 \mathrm{~V}: 4 \mathrm{H}$, even if skidded, there was a possibility the passengers may survived from death and suffered injuries only.

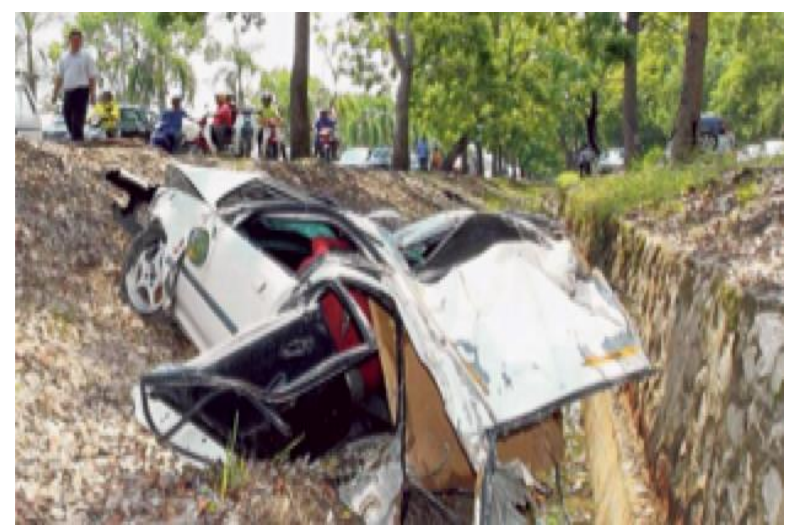

Figure 5: Fatal Accident at Roadside Drain (Source: Kosmo, 10 December 2015) 
If the roadside tree and the drain were positioned outside the study recommended safety recovery corridor, the passengers may survive both deaths and injuries. The tragedy has given evident that the drain design is not forgiving and need to be reconstructed with a new design. It is recommended that the drain to be reconstructed with a new design by applying the design concept recommended by the Malaysian standard as shown in Figure 8 (a). The redesign cross-section with enhanced safety of the highway and the sling road are shown in Figure 6 (a) and (b). The discharge capacity of swale is the combination of on the surface capacity, the perforated conduit volume and the interstices of sand and gravel. The volume of runoff to be served is minimal i.e. it is between the centre lines of the highway and sling roads about 20 meters width.

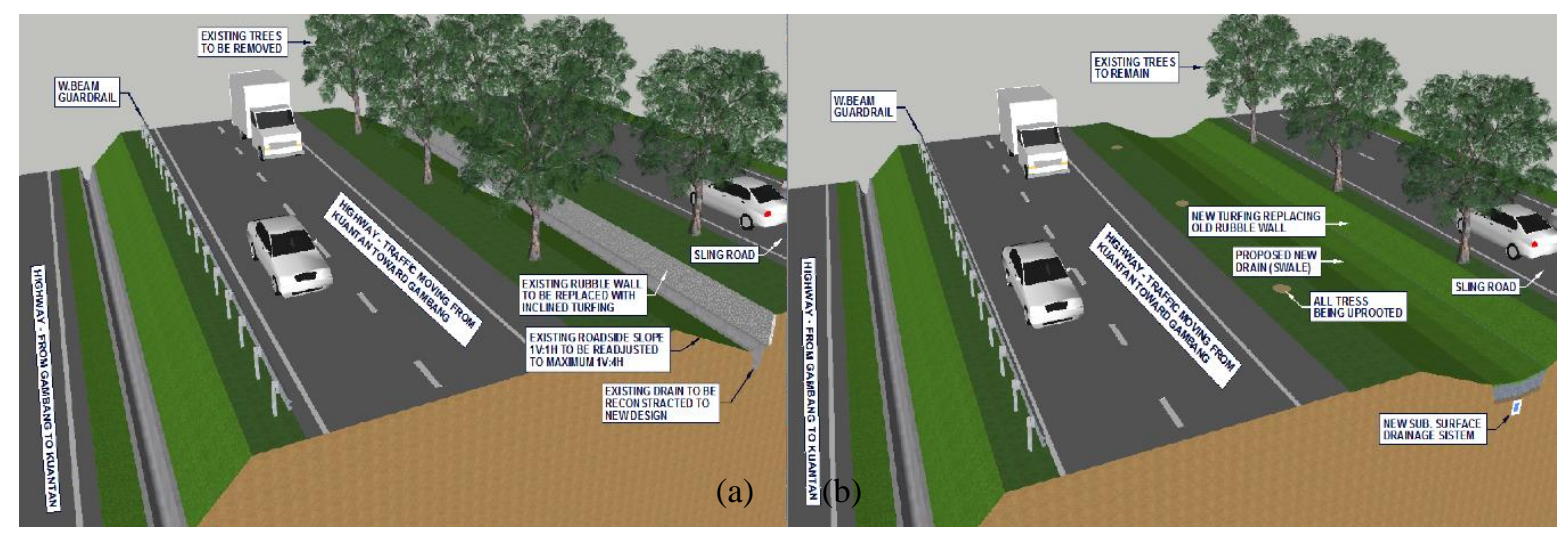

Figure 6: (a) Proposed reconstruction to the site shown in Figure 4; (b) Proposed design upgrade to the existing road shown in Figure 4

Figure 7, shows a bus skidded into roadside drain located at less than 2 meters away from the travel lane. The bus was avoiding collision from the oncoming car encroaching its lane, but unfortunately the roadside drain is to near to travel lane causing the bus has no space for traversing back to the carriageway. The tragedy evident that all drain to be built away from safety recovery zone corridor in order to ensure motorists safety. If placing drain outside safety corridor zone is unavoidable, the chosen type of drain shall be of traversable type, similar to the previous case employing swale design concept as shown in Figure 8 (a) The similar drain if located at the back-slope, apply cross-sectional design shown Figure 8 (b).

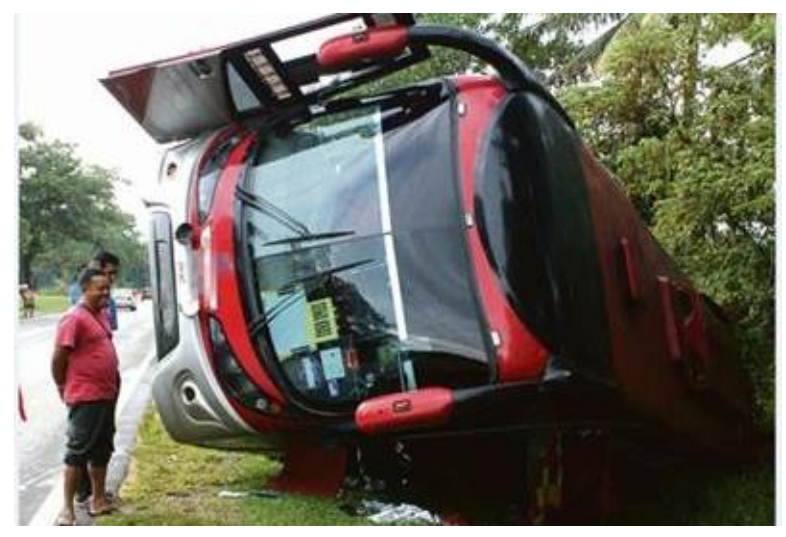

Figure 7: A bus flip over at roadside drain (Source: Ammboi, 20 October 2013)

The volume 4 of section 4.3.3 states that concealed roadside drains are preferred compared to exposed drains, and three proposed sections are shown in the text [28]. The guide provides three typical design for surface toe drains with embankments made of earth, concrete and stoned-lined with maximum slope of $1 \mathrm{~V}: 1.5 \mathrm{H}$. The maximum drain wall slope is $1 \mathrm{~V}: 1 \mathrm{H}$ for interceptor and berm drain 
placed on the embankment wall. The guide recommends use of swale for roadside drainage for environmental consideration as shown in Figure 8 (a). The swale section having low gradient wall and made of soft material sand and soil is ideal replacement to concrete or rubble lined drain wall.

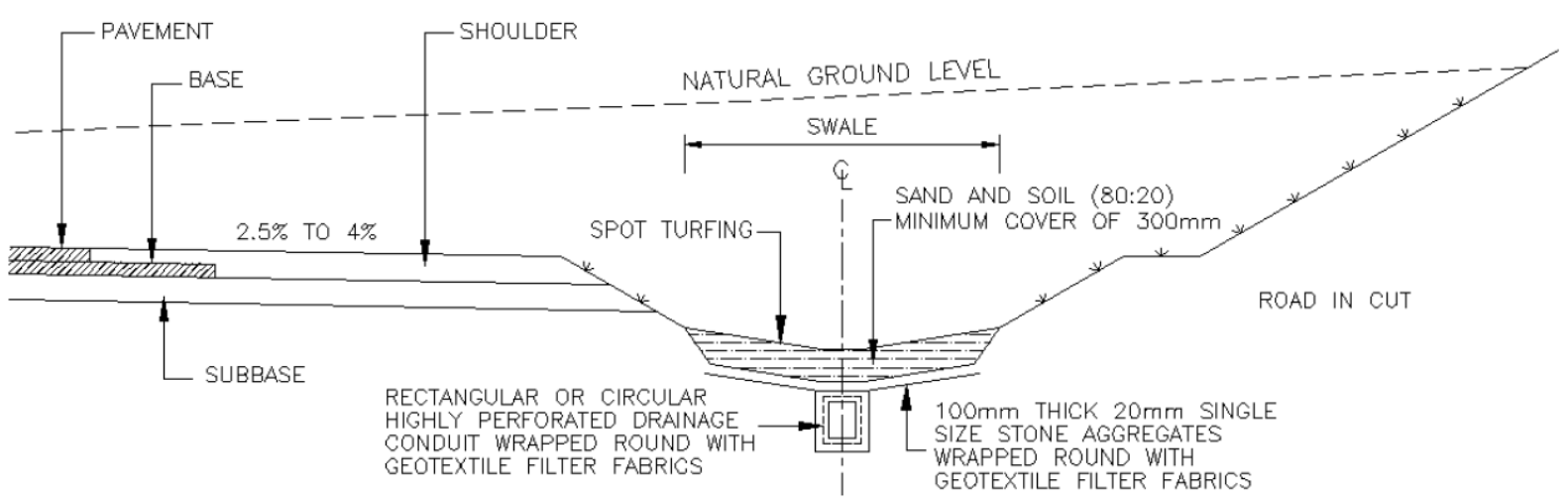

(a)

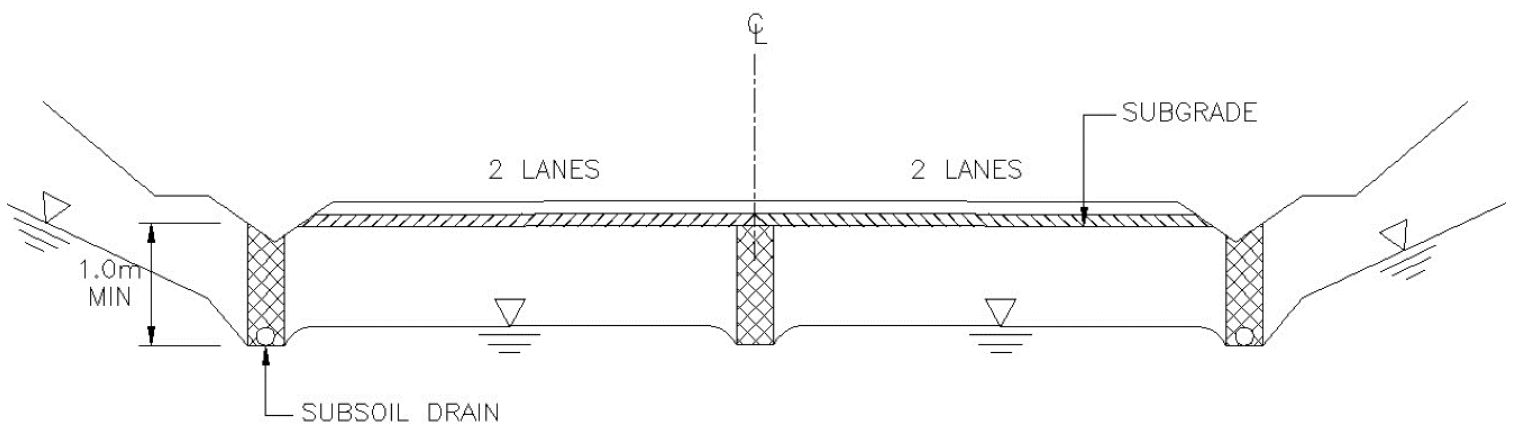

(b)

Figure 8: (a) Cross-section of Swale located at roadside; (b) Cross-section of roadside subsoil drain [25]

The volume 5 of the Guidelines for Road Drainage Design titled as Subsoil Drainage has some useful tools applicable to existing drainage if the drain cannot be relocated outside the safety recovery zone. The guide permit the use of subsoil system for main drainage line beside for intercepting seepage water from surrounding it and removal of stationary water, and be used to drain the subgrade and pavement surface runoff. Figure 8 (b) shows a typical design of roadside subsoil drain for multiple lanes road. In combination with the swale system, the subsurface drainage provides excellent tool for roadside drainage system.

\subsection{Case Study on Hazard Type 4: Kerbs}

Poorly designed kerbs causing damages upon collision to tyre sidewalls, wheel alignment, sometimes burst and may lead to fatal accidents on prolonged usage. Straying off from travel lane, wheel contact with kerbs could cause a vehicle to airborne and overturn. The 'forgiving' type kerb known as 'mountable kerb' is one of the two classes of kerbs recommended for application in design by the Malaysian standard known as A Guide on Geometric Design of Roads issued by the Road Engineering Association of Malaysia (REAM) under section 5.4.2 [25]. The other type of kerb recommended by the design standard is known as 'barrier kerb', though appear to be small in size but the force on impact with the concrete block may cause fatal accident as in the case shown in Figure 9, the motorcar hit the kerb then airborne killed 4 at kilometer 9.9 Elite highway Subang Jaya. The section 5.4.2 prohibits the use of barrier kerb for expressways or design speeds exceed $70 \mathrm{~km} / \mathrm{h}$, and the recommended use in build-up areas adjacent to footpaths with considerable pedestrian traffic. If mountable kerb is applied, the motorcar will rise over the kerb, dissipate part of the impact energy and the subsequent reduced 
impact energy on the roadside may not be fatal but with injuries. In enhancing the road safety campaign, auditing and correcting nationwide roadside kerb can be added to the agenda.

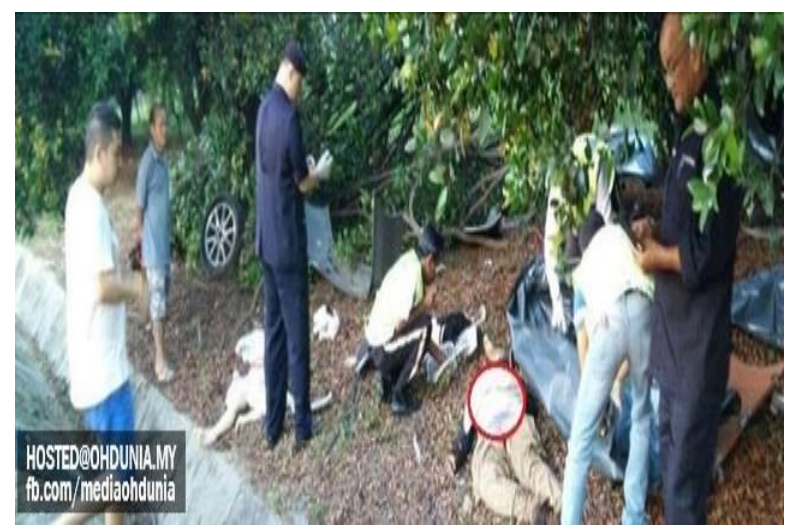

Figure 9: Fatal accident of a motorcar after hit a kerb. (Source: Ohdunia, 26 July 2015)

The Malaysian most recent practice is governed by the Guidelines on Design and Selection of Longitudinal Traffic Safety Barrier published by Road Engineering Association of Malaysia REAM in collaboration with Jabatan Kerja Raya Malaysia [29]. It is the revision of the previous manual known as Manual on Design Guidelines of Longitudinal Traffic Barrier issued by Cawangan Jalan JKR. Highway traffic barriers placed on road shoulder are to prevent encroachment into steep embankments or hitting harmful objects, and placed on medians to prevent collision with opposing traffic. Traffic barriers are hazards in nature, and hence their application must be well justified and reduced. The prescribed function of guardrails are to protect vehicle occupants from potential severe injuries instead of protecting roadside objects or preventing accidents. The engineer has to weigh and satisfy himself that placing the guardrails next to roadside object offer better protection to vehicle occupants than without them. Two types of traffic barriers named in the manual are longitudinal barriers and crash cushions. However, only longitudinal barriers are being detailed. The longitudinal traffic barrier works by diverting errant vehicles away from the protected hazards whilst crash cushion barriers decelerate errant vehicles to stop, resulting minimised head-on impact. The three barrier constructions are concrete, w-beam guardrail and wire rope safety fence.

\subsection{Case Study on Obstruction Type 5: Roadside Barriers}

Prior to installing longitudinal roadside barriers to shield fixed objects classified as hazards located within the clear zone of the minimum 6 meters specified under section 2.4.1 of the Guidelines on Design and Selection of Longitudinal Traffic Safety Barrier, an engineer has to consider removal, relocation or making the obstacle to be breakaway or collapsible [29].

The guardrail itself can be a roadside hazard as shown in Figure 10 (a), an accident at kilometre 13 Jalan Kuantan-Pekan, where the bus front left tyre exploded and then stroked into roadside longitudinal safety barrier has caused the metal beam punctured through the bus [30]. One passenger leg was broken and two passengers were with minor injuries. The reduced risk factor is due to the high elevation of the bus as compared to that of safety barrier height. The safety barrier installed was to shield the row of trees planted within the clear zone of 6 meters. Based on the guidelines, the trees are not permissible to be within the clear zone, and the instruction is a safety barrier is to be provided when the trees cannot be removed or relocated. In this case, the trees to be relocated at the offset of 6 meters from the travel lane due to available, otherwise the trees to be removed. 


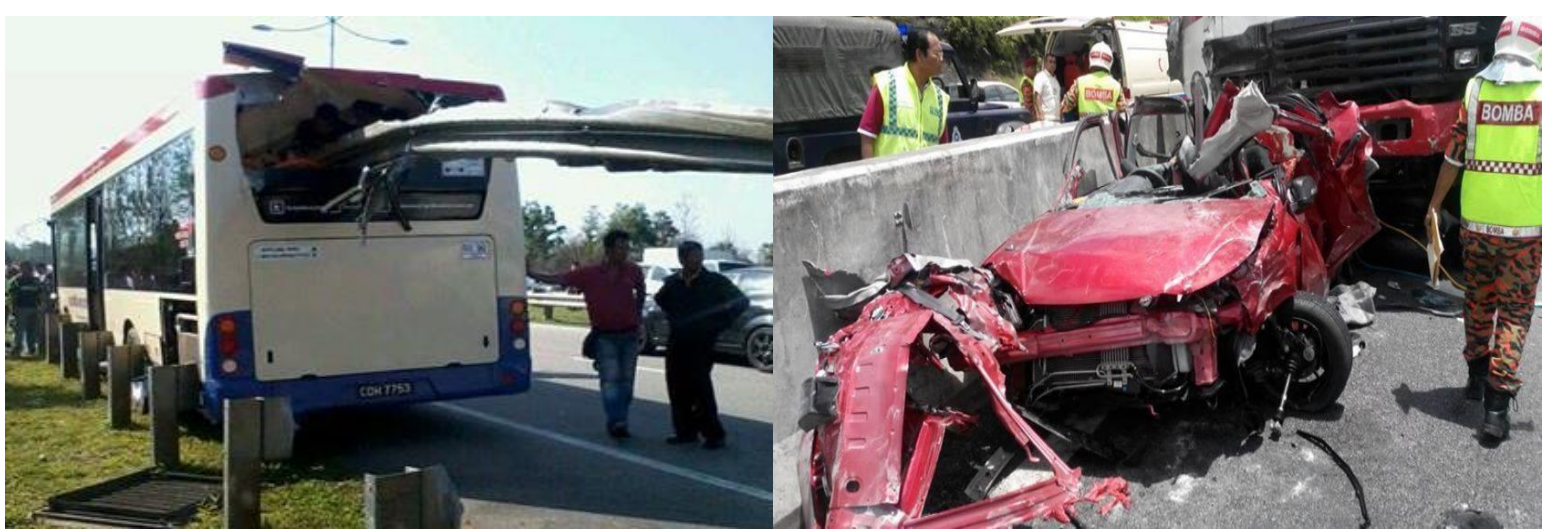

Figure 10: A metal beam punctured through the Rapid Kuantan Bus; (b) A car crashed into concrete wall

(Source: Melvister, 4 October 2014)

Figure 10 (b) shows a car crashed into concrete wall and caused two people died from the family at km 256 PLUS highway. The barrier is of the rigid type and its function is to redirect the vehicle upon collision where the dissipated energy will be absorbed by the vehicle and causing the metal body to deform, and sometime lead to fatal accident. It is recommended quay fender be lined to the side of concrete barrier wall at accident prone location as shown in Figure 11.

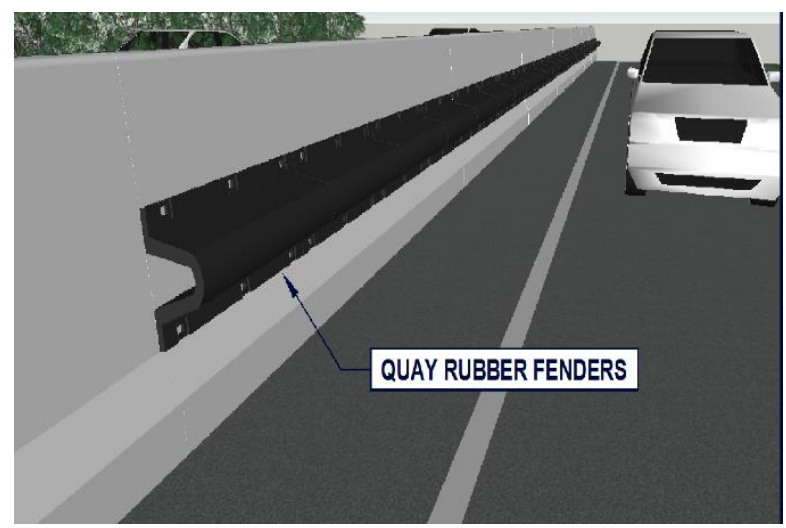

Figure 11: Quay rubber fender can be lined to the surface of concrete wall

\section{CONCLUSIONS}

Comparative study between the existing roadside structures to that recommended by the design guidelines shows interesting conflicting facts between the design intents and executed in construction. Assessment made against the design guidelines showed a number of incompliances. The study suggests that reviewing the guidelines and auditing their outcomes will minimise fatal accidents.

\subsection{Hazard Type 1: Tree}

Based on the above case study on collisions between motorcars and trees which were small were planted but grown big over time and become hazards, it is recommended that the Malaysian landscape design guide text Clause 4.1 which reads "Clear zones is defined as the area adjacent to the road pavement to the first tree (of diameter greater than $100 \mathrm{~mm}$ ) planted" shall be rephrased as "Clear zones is defined as the area adjacent to the road pavement to the first tree planted" i.e. with the elimination of the phrase "(of diameter greater than $100 \mathrm{~mm}$ )". Further, it is recommended to remove the last paragraph under the same section which reads as "Only shrubs and trees of diameter less than $100.00 \mathrm{~mm}$ are recommended to be planted within the clear zone". 


\subsection{Hazard Type 2: Poles}

There is no statement on clear zone in design guidelines related to installation of utility and signboard poles, construes that no consideration is mandatory in providing sufficient space for skidding vehicle to recover back to travel lane as in the case for landscaping trees. The case study revealed the fatal accidents involving poles and post, and proved the need for them to be placed outside the safety recovery zone.

\subsection{Hazard Type 3: Drains and Culverts}

The Malaysia design guideline requires drainage design to be integral part of road geometric design However in the text, there is nothing address on drainage system to be treated as roadside hazard. Based on the case study, numerous accidents evidenced that being a roadside hazard, drains and culverts have been contributing to fatal accidents. As required in the design guide that drainage to be integral with road geometric design, it is recommended that a paragraph that prohibits its encroachment into the safety recovery zone to be added in Malaysia design guidelines.

\subsection{Hazard Type 4: Kerbs}

In enhancing the road safety campaign, auditing and correcting nationwide roadside kerb can be added to the agenda. The existing design guide has provided sufficient and clear information on the application of roadside kerbs. The sharing point to the design engineer is to observe on the kerb design requirements. It is recommended to apply a soft and displaceable barrier having higher impact tolerance than hard semi-rigid barrier. Application of stacked gunny sandbags to a metre height is a cheaper and safer alternative than the metal barrier, thus giving a better chance of survival to the vehicle passengers. The side of the gunny sandbags facing the travel lane can be painted with a type of luminous paint to guide traffic at night. Alternatively, coloured tough plastic sandbags can be used.

\subsection{Hazard Type 4: Roadside Barrier}

A design engineer to give full consideration to removal, relocation or making the obstacle breakaway or collapsible before application of longitudinal roadside barriers. He has to ensure that provision of barrier gives better potential outcome on collision than without it. It is recommended for concrete barrier to be lined with quay rubber fender at locations subjected to frequent collisions based on past accident records.

\section{REFERENCES}

[1] Jabatan Keselamatan Jalan Raya. "Pelan Keselamatan Jalan Raya Malaysia 2014-2020". Jabatan Keselamatan Jalan Raya \& Institute Penyelidikan Keselamatan Jalan Raya Malaysia (MIROS). 2014

[2] United Nations. "The united nations and road safety". Retrieved from http://www.un.org/en/roadsafety/. Accessed on 25 November 2016.

[3] American Association of State Highway and Transportation Officials. "Roadside design guide 4th. Edition". 2011

[4] RISER Consortium. "European Best Practice for Roadside Design: Guidelines for Roadside Infrastructure on New and Existing Roads". Chalmers University of Technology. 2005

[5] Freeman P., Neyens D. M., Wagner J., Switzer F., Alexander K, Pidgeon P. "A video based runoff-road training program with practice and evaluation in a simulator”. Accid. Anal. Prev. (2015), 2015

[6] National Highway Traffic Safety Administration. "Traffic Safety Facts 2011: A Compilation of Motor Vehicle Crash Data from the Fatality Analysis Reporting System and the General Estimates System”. DOT HS 811 754. Department of Transportation, Washington, D.C, 2013 
[7] Carlos Roque, Filipe Moura, João Lourenço Cardoso. "Detecting unforgiving roadside contributors through the severity analysis of ran-off-road crashes". Accid. Anal. Prev. 80, 262-273, 2015

[8] European Road Safety Observatory. "Traffic Safety Basic Facts 2012: Single Vehicle Accidents”. 2012

[9] National Highway Traffic Safety Administration. "NCSA Data Resource Website: Fatality Analysis Reporting System (FARS) Encyclopedia". 2014

[10] Chen Z., Wu C., Zhong M., Lyu N., Huang Z. "Identification of common features of vehicle motion under drowsy/distracted driving: A case study in Wuhan, China". Accid. Anal. Prev. 81, 251-259, 2015

[11] Jennie Connor, Robyn Norton, Shanthi Ameratunga, Elizabeth Robinson, Ian Civil, Roger Dunn, John Bailey, Rod Jackson. "Driver sleepiness and risk of serious injury to car occupants: population based case control study". Brit. Med. Jour. 324 (7346), 1125, 2002

[12] Thiffault P., Bergeron J. "Monotony of road environment and driver fatigue: a simulator study". Accid. Anal. Prev. 35, 381-391, 2003

[13] Wilson, F. A., Stimpson, J. P. "Trends in fatalities from distracted driving in the United States 1999-2008". Am. J. Public Health. 100(11), 2213-2219, 2010

[14] Hallvig D., Anund A., Fors C., Kecklund G., Karlsson J. G., Wahde M., Akerstedt T. "Sleepy driving on the real road and in the simulator - a comparison". Accid. Anal. Prev. 50, 44-50, 2013

[15] Saifuzzaman, M., Haque, M.M., Zheng, Z., Washington, S. "Impact of mobile phone use on carfollowing behaviour of young drivers". Accid. Anal. Prev. 82, 10-19, 2015

[16] Neale V. L., Dingus T. A., Klauer S. G., Sudweeks J., Goodman M. "An Overview of the 100-car Naturalistic Study and Findings”. National Highway Traffic Safety Administration. 05-0400, 2005

[17] Bamback M. R. and Mitchell R. J. "Safe system approach to reducing serious injury risk in motorcyclist collisions with fixed hazards". Accid. Anal. Prev. (2015) 74, 290-99. 2015

[18] Insurance Institute for Highway Safety. "Collisions with fixed objects and animals". Retrieved from http://www.iihs.org/iihs/topics/t/roadway-and-environment/fatalityfacts/fixed-objectcrashes. Accessed on 2 February 2016

[19] Torre F. L. "Forgiving Roadsides Design Guide". Conference of European Directors of Roads (CEDR). November 2012.

[20] Mak K. K., Sicking D. L. "Roadside Safety Analysis Program - Engineer's Manual”. National Cooperative Highway Research Program (NCHRP) Report 492. Transportation Research Board, Washington D.C. 2003

[21] Kunji A. K., Ali, N. M., Zulkiple A. "Safety Recovery Zone Corridor for Malaysian Roads Derived From Live Field Experiments". Proceeding of International Seminar on Slope and Road Foundation Drainage and Stormwater Management. 9 - 13 November 2014.

[22] Jabatan Kerja Raya. "Intermediate Guidelines to Road Reserve Landscaping". Nota Teknik (Jalan) 19/97. 1997

[23] National Landscape Department. "National Landscape Policy issued by the Ministry of Housing and Local Government”. 1996

[24] "Man Killed when Car Rams Tree". Borneo Post Online. Retrieved from http://www.theborneopost.com/2012/08/13/man-killed-when-car-rams-tree/. Accessed on 25 November 2016

[25] Road Engineering Association Malaysia. "Guidelines 2/2002: A guide on geometric design of roads". Road Engineering Association of Malaysia (REAM). 2002

[26] Road Engineering Association Malaysia. "Guidelines 3/2004 Vol. 1: Guideline for Road Drainage Design, Hydrological Analysis - Estimation of Design Floods". Road Engineering Association of Malaysia (REAM). 2004

[27] Ross H. E., Sicking D. L., Hirsch T. J., Cooner H. D., Nixon J. F., Fox S. V, and Damon C. P. "Safety Treatment of Roadside Drainage Structures". Transportation Research Record 868. TRB, National Research Council. 1982. 
[28] Road Engineering Association Malaysia. "Guidelines 3/2004 Vol. 4: Guideline for Road Drainage Design, Surface Drainage”. Road Engineering Association of Malaysia (REAM). 2004

[29] Road Engineering Association Malaysia. "Guidelines 9/2006: Guidelines on Design and Selection of Longitudinal Traffic Safety Barrier". Road Engineering Association of Malaysia (REAM) in collaboration with Jabatan Kerja Raya Malaysia", 2006

[30] "Bus punctured by roadside barrier".Sinar Harian. Retrieved from http://www.sinarharian.com.my/kolumnis/bas-tertusuk-besi-penghadang-jalan-1.291337. Accessed on 25 November 2016 